\title{
AMÉRICA SIII MOMBPBE
}

ISSN: 1989-9831

Núm. 26, 2022, pp. 163-166

https://doi.org/10.14198/AMESN.2022.26.11

\section{Erika Martínez (ed.). Materia frágil. Poéticas para el siglo XXI en América Latina y España. Madrid-Frankfurt am Main: Iberoamericana-Vervuert}

Autora

EsTHer Soro

Universidad de Alicante, España

esther.soro@ua.es

(iD) https://orcid.org/0000-0002-1674-5985

\section{Citación}

Soro, Esther. «Erika Martínez (ed.). Materia frágil. Poéticas para el siglo XXI en América Latina y España. Madrid-Frankfurt am Main: Iberoamericana-Vervuert». América sin Nombre, 26 (2022): pp. 163-166. https://doi. org/10.14198/AMESN.2022.26.11

\section{Resumen}

Reseña de Esther Soro sobre Materia frágil. Poéticas para el siglo XXI en América Latina y España. (Iberoamericana, 2020) de Erika Martínez. 343 pp. ISBN: 978-849192-127-1. [Review of Esther Soro sobre Materia frágil. Poéticas para el siglo XXI en América Latina y España. Iberoamericana (2020) de Erika Martínez. 343 pp. ISBN: 978-84-9192-127-1]

Palabras clave: América Latina; Maeria frágil; siglo XxI; Esther Soro; Erika Martínez.

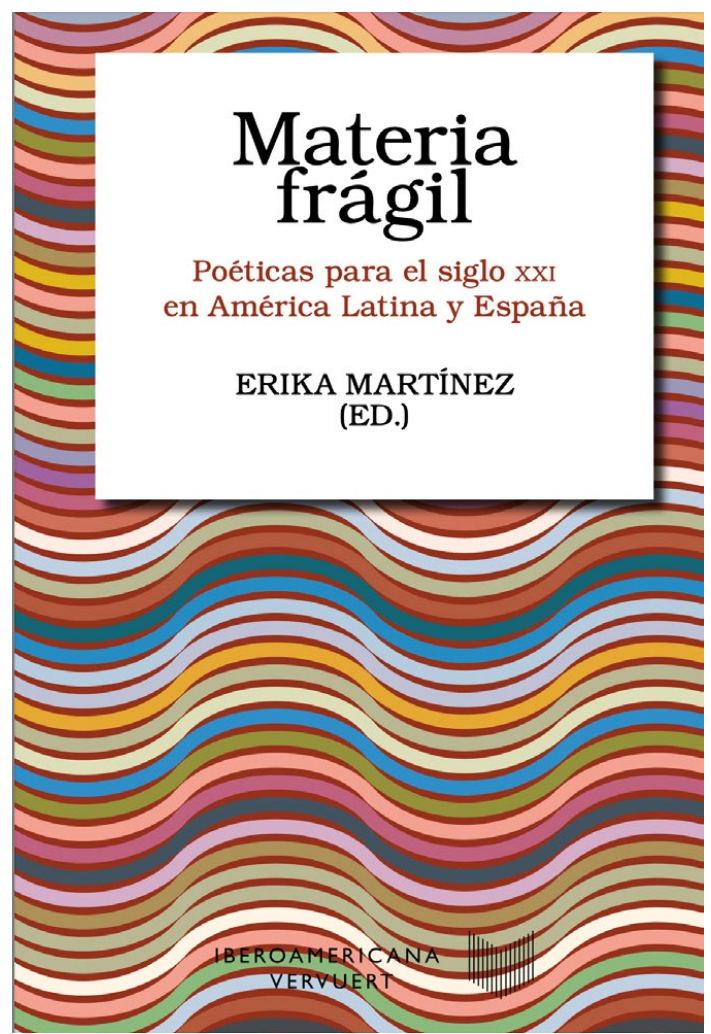

Pensar las poéticas del siglo xxI y, sobre todo, estructurarlas y cohesionarlas es uno de los principales retos a los que se enfrenta la crítica literaria actual. Este volumen de ensayos, editado por la estudiosa y poeta Erika Martínez, configura sin duda 
un avance determinante en dicha labor. Con él, tal y como expone Martínez en la «Presentación» del libro, se tratan de mostrar las perspectivas fundamentales a través de las que abordar y transitar la heterogénea y fragmentaria materia poética actual de España y Latinoamérica.

Materia frágil. Poéticas para el siglo XXI en América Latina y España está conformado por diecisiete ensayos, a los que se suma una crónica poética y una breve presentación de los autores. Todo ello aparece dividido en cuatro bloques: «I. Recorridos», «II. Aproximaciones», «III. Resonancias» y «IV. Epílogo».

El primero de los apartados tiene como propósito trazar «horizontes poéticos colectivos" (10); es decir, establecer las coordenadas que, a un lado y otro del Atlántico, rigen los principales proyectos poéticos de la actualidad. De este modo, los dos textos iniciales de dicho apartado, «Hacer aguas o la materia decible del poema en América Latina y España» de Erika Martínez y «Transmedialidad y campo poético: un recorrido por América Latina» de Gustavo Guerrero, sintetizan algunas de las características esenciales de la poesía última: en primer lugar, se destaca la influencia que la globalización y la tecnofilia han tenido en el predominio de la trasmedialidad y la digitalización en el ámbito literario. En segundo lugar, la voluntad de los poetas de romper con el individualismo generalizado ha dado lugar a un interés de los escritores por lo colectivo y lo colaborativo, que se traduce en una mayor presencia de la performatividad, la poesía visual y el cuestionamiento del yo lírico. En tercer lugar, se advierte también un afán por la atención a lo marginal y lo subversivo, que de algún modo se vincula con la constante tensión entre tradición y modernidad que se aprecia en las obras, así como con el gusto por la relectura y reinterpretación de la historia y de los clásicos. Tras esta exposición, ambos críticos concluyen que, para auscultar una materia poética tan compleja y ecléctica, es necesario dejar a un lado perspectivas formalistas y contextuales en pos de investigaciones centradas en estudiar la plasticidad y porosidad de la poesía del nuevo milenio.

Esta apertura y adaptación metodológica a la que apuntan Erika Martínez y Gustavo Guerrero es la que encontramos en los ensayos sucesivos del volumen. Así, el resto de trabajos que componen el apartado «I. Recorridos» profundizan en el análisis de la configuración de todas esas características generales en propuestas literarias concretas. Sin embargo, lo hacen desde una perspectiva panorámica, cuyo principal objetivo es enfatizar los vínculos comunes existentes entre diferentes autores y colectivos. De este modo, Magda Sepúlveda, en «¿Cómo llegamos a la promoción poscoma del siglo Xxi? De cómo las minorías se van tomando la palabra», y María José Bruña Bragado, en «Algunas poéticas disidentes en el Uruguay de finales del siglo xxI: Clemente Padín, Luis Bravo y Maca», examinan de qué manera las poesías chilena y uruguaya, respectivamente, han hecho frente a las limitaciones impuestas por los complejos contextos sociopolíticos en los que se desarrollan. En los ensayos de Luciana di Leone, «Mujeres que escriben, mujeres que hablan, mujeres que se escuchan: un horizonte colectivo para la poesía brasileña contemporánea», y Victoria 
Guerrero, «Poetas peruanas últimas: ¿qué dicen, qué piensan?», se apuesta por un estudio de la obra poética escrita por mujeres: la primera de ellas trata de evidenciar, a través del análisis de colectivos como Abrasabarca, Mulheres que Escrevem y Slam das Minas, la relevancia que este tipo de agrupaciones tiene en la construcción de redes políticas y culturales, así como en la visibilización y circulación de los discursos femeninos. Por su parte, el texto de Guerrero, a pesar de exponer las propuestas poéticas individuales de tres autoras, Valeria Román, Myra Jara y Rosa Granda, se centra en subrayar los lazos y puntos de conexión entre ellas, con el fin de mostrar cómo estos posibilitan la reflexión en torno a la condición identitaria de la mujer en el Perú del siglo xxi. Este tipo de nexos se potencian además gracias a acontecimientos públicos como conferencias, jammings, coloquios, festivales, etc., cuestión que también trabaja Almudena Vidorreta en su ensayo «Panorama neoyorquino de la poesía reciente en lengua española, con algunas notas sobre su traducción».

En el segundo de los apartados, «II. Aproximaciones», asistimos ahora sí al estudio de poéticas individuales. Con ello se trata de hacer manifiesto cómo esos rasgos generales se perfilan y concretan en la obra de autores específicos. De esta manera, por ejemplo, en los estudios de Ben Bollig, «Maternidad y nueva lírica: Madre soltera de Marina Yuszczuk», y Jenny Haase, «Poética de la criatura: Animales pequeños de Lucia A. Mellado», sobre la obra de Yuszczuk y Mellado, se observa el modo en el que el yo lírico se fragmenta en los textos con la intención de explorar la complejidad que supone la experiencia humana y, más aún, la experiencia humana femenina en un contexto hostil y opresor. Estas temáticas a propósito del papel de la mujer en la sociedad actual son también abordadas en trabajos como el de Sergio Raimondi, «Las comandantas, o sobre la poesía de Fernanda Laguna», en el que el crítico ahonda en los nuevos modos de combate y revolución que Laguna propone en su obra, y que se expresan mediante una retórica rupturista y fragmentada, en la que la presencia de la duda, lo inexacto e, incluso, lo erróneo son fundamentales para la deconstrucción de la subjetividad. En una línea similar discurre el ensayo de Berta García Faet, «La poesía de Emma Villazón. Figuras alternativas de hijas y niños: sin padres, sin patrias, sin patrón», que analiza, a propósito de la literatura de Villazón, cómo la dilución de los sujetos va ligada a una reflexión sobre la manera en la que la violencia patriarcal afecta también genealógica y socioeconómicamente a la mujer. Asimismo, el estudio de Gracia Morales Ortiz, «Elementos dramatúrgicos en Antígona González de Sara Uribe: estrategias para nombrar el horror», penetra en esa voluntad rupturista y subversiva de la poesía actual, que se refleja en la superposición y disrupción de los géneros literarios tradicionales. Ese afán renovador, sin embargo, no impide que en las obras encontremos también un interés por la recuperación y reinterpretación de la tradición literaria, hecho en el que se centran los estudios de Julio Prieto, «Haciendo solitarios con Adorno: en torno a Cantos de concentración de Pablo de Cuba», o Marta López Vilar, "Construir la escritura y el sujeto desde los restos del pasado: el paradigma de la poesía de Susanna Rafart». Por 
todo ello, este segundo apartado nos muestra cómo todas esas propuestas poéticas individuales, a pesar de su heterogeneidad y pluralidad, forman parte de un mismo sentir literario común.

En el tercero de los bloques, «III. Resonancias», encontramos tres ensayos, dos de los cuales profundizan en dos autores puente fundamentales, en cuya obra se aprecia el avance de la poética del siglo xx a la del siglo xxi: por un lado, el trabajo de Álvaro Salvador Jofre, «El equilibrista en el vacío: sobre Eduardo Chirinos», evidencia cómo en la obra de Chirinos se observa una evolución de una estética más culturalista hacia un mayor experimentalismo, que se manifiesta, por ejemplo, en el entramado lúdico de voces poéticas o en el mayor interés por el coloquialismo. Por otro lado, el análisis de Vicente Cervera Salinas, «El siglo XXI de Piedad Bonnett», aborda la etapa de madurez de la obra de Bonnett, centrándose en examinar cómo en ella se erige lo que el crítico cataloga como una "poética del desaliento», en la cual las resonancias de poetas como Rilke, Vallejo o Varela tendrán una importancia capital. Ambos textos, por tanto, apuntan a cómo el cambio epistemológico que trajo consigo el nuevo milenio se reflejó incluso en la producción de autores ya entrados en su madurez literaria. De manera análoga, la llegada del siglo xxi dejó su impronta también en el modo en que desde los círculos culturales e institucionales se recibió y se reinterpretó la tradición literaria anterior. En ese sentido, es iluminador el último de los ensayos, "Juego y secreto: Rosalía de Castro como figura gótica», en el que María do Cebreiro Rábade Villar estudia la forma en que, ya desde el siglo XIX, se llevó a cabo una mitificación de la figura de Rosalía de Castro, la cual actualmente ha desembocado en propuestas neoliberales que no hacen sino poner la figura de la poeta al servicio de las querencias mercantiles, devaluando, pero, al mismo tiempo, resignificando su iconicidad.

Por último, en el apartado «IV. Epílogo», Héctor Hernández Montecinos nos permite acompañarlo durante su trayecto hacia La Paz, a través de una crónica conformada por doce líricos y sugerentes fragmentos en los que comparte reflexiones acerca de la poesía, el papel del escritor, la identidad nacional o la orientación sexual. Esa suerte de mosaico impresionista, construido mediante evocaciones y retazos poéticos, configura, sin duda, el broche perfecto con el que cerrar el volumen.

Materia frágil. Poéticas para el siglo XXI en América Latina y España, por tanto, constituye un muestrario, una maraña de ejemplos metodológicos que nos permiten descubrir nuevos modos a través de los cuales explorar la producción poética actual en América Latina y España. Por todo ello, el libro evidencia cómo el estudio de estas nuevas poéticas ha de confeccionarse, paradójicamente, a partir de la búsqueda de la conexión en el fragmento, de la coherencia en lo diverso; en definitiva, de la solidez en la fragilidad. 